\title{
MOUSE BRAIN DISTRIBUTION OF A CARBON-11 LABELED VESAMICOL DERIVATIVE: PRESYNAPTIC MARKER OF CHOLINERGIC NEURONS
}

Michael R. Kilbourn*, Yong-Woon Jung, Michael S. Haka, David L. Gildersleeve, David E. Kuhl and Donald M. Wieland

Division of Nuclear Medicine, Department of Internal Medicine, University of Michigan, Ann Arbor, MI 48109

(Received in final form September 18, 1990)

\section{Summary}

The regional mouse brain distribution of a new carbon-11 labeled derivative of vesamicol, [11 C]-5-(N-methylamino)benzovesamicol ([11C]MABV) is reported. Radiotracer concentrations in vivo are in the rank order of striatum $>$ cortex $>$ hippocampus $>$ hypothalamus $>$ cerebellum, consistent with reported distributions of other presynaptic cholinergic neuronal markers. In time course studies, striatum/cerebellum and cortex/cerebellum ratios for (-)-[11C]MABV continue to increase to values of 13 and 5 , respectively, 75 min after i.v. injection of [11C]MABV. The specific binding in striatum and cortex is lowered by pretreatment with ( \pm )-vesamicol, and shows stereoselectivity with lower uptake and lower ratios for the (+)-enantiomer. (-)[11C]MABV is proposed as a positron-emitting radioligand for the in vivo study of presynaptic cholinergic neurons.

Alzheimer's disease is characterized by degeneration of the cholinergic neurotransmitter system. The unique biochemical characteristics of the cholinergic neuron, such as high affinity choline uptake (HAChU), choline acetyltransferase (ChAT), and vesicular storage of acetylcholine have been thoroughly studied in vitro using radiotracer or immunochemistry techniques. Declines in ChAT and HAChU, as well as in acetylcholınesterase, are now widely recognized features of the neurochemical pathology in Alzheimer's disease $(1,2,3)$. Radiotracers which mark specific presynaptic biochemical processes of cholinergic neurons might be useful for assessment of changes in function or number of such terminals in vivo using positron emission tomography (PET). Vesamicol (2-(4-phenylpiperidino)cyclohexanol: AH5183) binds to a specific site on presynaptic acetylcholine storage vesicles where it acts as a stereoselective, non-competitive, allosteric inhibitor of acetylcholine uptake into the vesicle $(4,5,6)$. We have prepared a high specific activity, carbon-11 $\left(\beta+, t_{1 / 2}=\right.$ $20.4 \mathrm{~min}$ ) labeled derivative of vesamicol, ( $\mathrm{N}$-([11C]methyl)-aminobenzovesamicol ([11C]MABV), and report here preliminary in vivo biodistribution results in mouse brain. 
<smiles>CNc1cccc2c1C[C@H](N1CCC(c3ccccc3)CC1)[C@H](O)C2</smiles>

Fig. 1. N-([11C]Methyl)-aminobenzovesamicol ([11C]MABV).

\section{Methods}

\section{Chemicals}

(-) -Vesamicol was obtained from Research Biochemicals, Inc. (Natick, MA). 5-Aminobenzovesamicol (ABV) was prepared by literature methods (5) and resolved by chiral HPLC (Chiracel OD column, $4.6 \times 250 \mathrm{~mm}$, hexane:isopropanol). Authentic N-methylaminobenzovesamicol was prepared from ABV by reaction of the aniline with benzylchloroformate and reduction of the intermediate with lithium aluminum hydride. The product fully characterized $\left(1 \mathrm{H}\right.$ and ${ }^{13} \mathrm{C}$ NMR, mass spec, $\mathrm{C}, \mathrm{H}, \mathrm{N}$ analysis).

[11C]MABV was prepared by $\mathrm{N}$-methylation of aminobenzovesamicol. [11C]Methyl iodide, prepared by standard methods (7), was bubbled into a solution of $\mathrm{ABV}$ (1 mg, as methanesulfonate salt) in $0.250 \mathrm{ml}$ of $\mathrm{DMF}$ at $-25^{\circ} \mathrm{C}$. The solution was heated to $125^{\circ} \mathrm{C}$ for 15 minutes, cooled, and injected onto the HPLC. Purification was done using a semi-preparative C18 column (Maxsil C18, 5 micron, $7.6 \times 300 \mathrm{~mm}$ ) eluted with $\mathrm{CH}_{3} \mathrm{CN} / \mathrm{CH}_{3} \mathrm{OH} / 11 \mathrm{mM} \mathrm{NaH}_{2} \mathrm{PO}_{4}(3 / 1 / 2.25$, v/v/v $), \mathrm{pH}=$ 7 , at $1 \mathrm{ml} / \mathrm{min}$. Retention times of $M A B V$ and $A B V$ were 17.5 and $24 \mathrm{~min}$, respectively. Isolated [11C]MABV was prepared for injection by evaporation of the HPLC solvent and dissolving the product in sterile saline. Yields were $15-20 \%$ (corrected for decay). Radiochemical and chemical purity, and specific activity, were obtained from a separate injection of formulated product on an analytical HPLC column : Maxsil C18, $4.6 \times 250 \mathrm{~mm}$; solvent system as above: $R_{t}$ MABV $=15 \mathrm{~min}, R_{t}$ $\mathrm{ABV}=10 \mathrm{~min}$. Radiochemical purity was further checked using thin layer chromatography (silica gel, $40 / 60$ hexane/ethylacetate, $R_{f}=0.4$ ). Full details of the synthesis of the cold and radioactively labeled compounds will be presented elsewhere (Jung et al in preparation).

\section{Regional Brain Distributions}

Regional brain distribution studies were performed in female CD-1 mice, 20-25 g (Charles River). For each data point 4-5 animals were used. Animals were anesthetized with diethyl ether and [11C]MABV $(50-75 \mu \mathrm{Ci}, 50-100 \mathrm{ng})$ injected via the tail vein. The animals were allowed to recover, then sacrificed by decapitation at designated times. A blood sample was obtained, and the brain rapidly removed and dissected into samples of striatum, occipital cortex, hippocampus, hypothalamus and cerebellum (8). Tissue samples were counted for carbon-11 and then weighed. Data was calculated as \% injected dose per gram (\% $\mathrm{ID} / \mathrm{g})$ of tissue, and \% ID/brain.

Pharmacological blocking studies were done by i.v. administration of 
( \pm )-vesamicol (300 $\mu \mathrm{g} / \mathrm{kg}, 100 \mu \mathrm{l}$ volume bolus injection) 10 minutes prior to radiotracer injection, followed by sacrifice and dissection according to the above protocol. test.

Data were analyzed for statistical significance using an unpaired Student's t-

\section{Metabolite Analysis}

Two animals were injected with approximately $100 \mu \mathrm{Ci}$ each of (-)-[11C]MABV. After 45 minutes, the animals were killed and the brains removed and dissected. Samples of the striatum were pooled and homogenized in a small volume $(0.1 \mathrm{ml})$ of $100 \%$ ethanol. The ethanol extract was analyzed by thin layer chromatography (silica gel, $50 / 50$ hexane/ethylacetate, $R_{f}=0.50$ ) and the distribution of radioactivity on the plate determined using a Berthold Automatic TLC-Linear Analyzer. In control experiments, 1 microcurie of authentic [11C]MABV was added to separate samples of striatal tissue from mouse brain, and the homogenization, extraction and chromatography steps performed as described above.

\section{Results}

The time course of regional distribution of (-)-[11C]MABV is shown in Figure 2. With the exception of the striatum, tissue radioactivity levels were highest at the early time point and steadily decreased. Striatal radioactivity levels were not significantly different at early and late time points.

The regional brain distributions of carbon-11 radioactivity 45 minutes after injection of the (+), (-) and racemic forms of [11C]MABV are compared in Table 1 . The highest radioactivity concentration in all cases was in the striatum and lowest in the cerebellum. The regional brain distribution of (+)-MABV at $45 \mathrm{~min}$ shows lower retention of radiotracer in all tissues, and significantly lower STR/CER and STR/CTX ratios for this isomer. At 75 minutes the tissue levels continue to decrease, giving lower STR/CER and STR/CTX ratios (data not shown). Regional radioactivity distribution for $( \pm)-[11 \mathrm{C}] \mathrm{MABV}$ after pretreatment with $300 \mu \mathrm{g} / \mathrm{kg}(-)$-vesamicol is also shown in Table 1 . Radiotracer accumulation was most reduced in the striatum $(-30 \%)$, but also lower in the cortex, hippocampus and hypothalamus (20-30\% reductions). Radiotracer levels in cerebellum and blood remained unaffected by vesamicol pretreatment.

Analysis of extracts of radioactivity from striatal tissues gave a radiochromatogram identical to that obtained in control experiments with authentic [11C]MABV, suggesting the presence of only unchanged [11C]MABV.

\section{Discussion}

Radiotracers specific for binding sites on presynaptic neurons have the potential to provide information on the in vivo integrity of specific neurotransmitter systems. Alone, such radiotracers might provide valuable information on the regional concentrations of neurons present in normal and diseased brain. Used in conjunction with measures of neurotransmitter synthesis rates, or of postsynaptic receptor densities, they may offer a method for more complete understanding of the normal function of synaptic processes and their possible malfunction in disease states. We have previously prepared such presynaptic markers for the dopaminergic (9), 

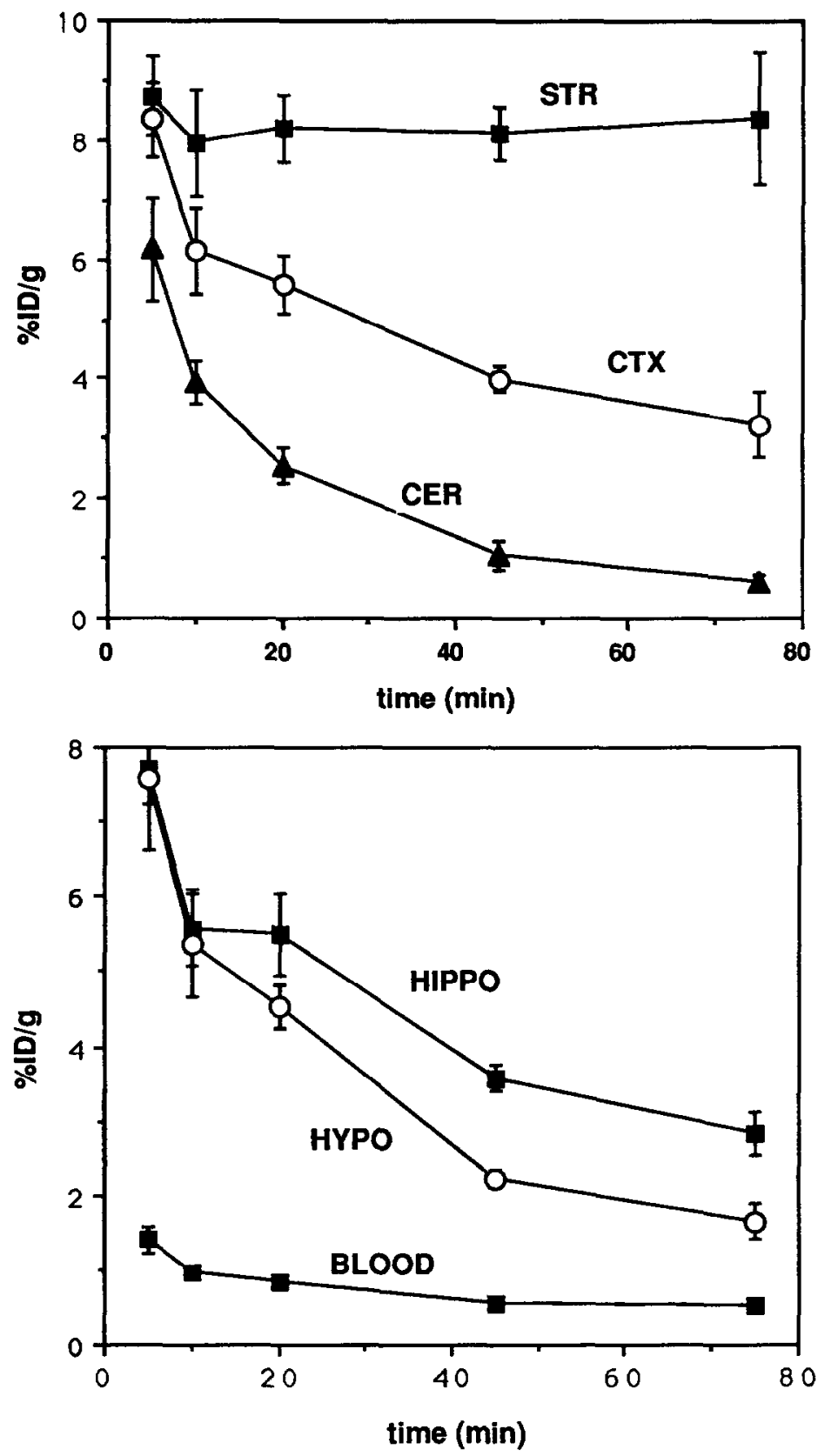

Fig. 2. Time course of $\left[{ }^{11} \mathrm{C}\right] \mathrm{MABV}$ uptake and retention in specific regions of mouse brain. Values shown are means \pm SD for four to six animals per time point. STR = striatum, CTX = cortex, $\mathrm{CER}=$ cerebellum, $\mathrm{HIPPO}=$ hippocampus, HYPO = hypothalamus. 


\section{TABLE I}

$\begin{array}{lll}(+) \mathrm{MABV}(-) \mathrm{MABV} & ( \pm) \mathrm{MABV} & ( \pm) \mathrm{MABV}+ \\ & & 300 \mathrm{mg} / \mathrm{kg} \\ & ( \pm) \text { vesamicol }\end{array}$

tissue

$\% \mathrm{ID} / \mathrm{g}^{+}$

\begin{tabular}{|c|c|c|c|c|}
\hline Striatum & $1.23 \pm .10^{*}$ & $8.1 \pm .44$ & $6.41 \pm .21$ & $3.91 \pm .49^{*}$ \\
\hline Cortex & $0.91 \pm .06^{*}$ & $3.99 \pm .22$ & $3.38 \pm .14$ & $2.33 \pm .26^{* *}$ \\
\hline Hippocampus & $0.93 \pm .04^{*}$ & $3.58 \pm .19$ & $3.23 \pm .65$ & $2.23 \pm .26^{* *}$ \\
\hline Hypothalamus & $0.88 \pm .04^{*}$ & $2.23 \pm .11$ & $2.22 \pm .09$ & $1.80 \pm .24$ \\
\hline Cerebellum & $0.73 \pm .07^{*}$ & $1.05 \pm .25$ & $1.09 \pm .04$ & $1.05 \pm .14$ \\
\hline Blood & $0.41 \pm .02^{*}$ & $0.54 \pm .03$ & $0.65 \pm .02$ & $0.61 \pm .04$ \\
\hline STR/CER & $1.75 \pm .23^{*}$ & 7.75 .18 & $5.81 \pm .28$ & $3.72 \pm .35^{* *}$ \\
\hline CTX/CER & $1.25 \pm .15^{*}$ & 3.81 .22 & $3.14 \pm .51$ & $2.23 \pm .27 * *$ \\
\hline STR/CTX & $1.36 \pm .2^{*}$ & 2.02 .08 & $1.91 \pm .24$ & $1.67 \pm .08$ \\
\hline \%dose/brain & $1.49 \pm .21$ & $1.46 \pm .16$ & $1.46 \pm .14$ & $0.97 \pm .09 * *$ \\
\hline
\end{tabular}

Regional Brain Distribution of $(-),(+)$ and ( \pm )-[11C]MABV in CD-1 Mouse Brain at 45 minutes after i.v. Injection.

noradrenergic (10), and GABA-ergic (11) systems, and the present work is an extension of this effort to the cholinergic system. Development of a presynaptic cholinergic marker for PET studies is similar to our recent efforts to prepare radioiodinated vesamicol derivatives for single photon emission computed tomography (SPECT) studies (12), and complements efforts in our laboratories and others to study postsynaptic muscarinic acetylcholinergic receptors using gammaemitting radiotracers (13-19).

Vesamicol binds in a high affinity, stereoselective fashion to a specific site on vesicles of cholinergic neurons. A large number of derivatives of vesamicol have been recently synthesized and several of these compounds show equal or better affinities for the vesamicol binding site (5). Of particular note are the derivatives of benzovesamicol (trans - 2-hydroxy-3-(4-phenylpiperidino)tetralin, IC $50=50 \mathrm{nM}$ ), in which considerable steric tolerance in the 5-position was evident in the structureactivity study. Substituents ranging from small (amino) to quite large (biotinylglycineglycine) are well tolerated (5). Vesamicol offers few good options for radiolabeling with carbon-11 or fluorine-18, but 5-aminobenzovesamicol (IC50 = 100 $\mathrm{nM})$ offers numerous possibilities for labeling with fluorine-18 $\left(\beta+, t_{1 / 2}=110 \mathrm{~min}\right)$ or carbon-11. $\mathrm{N}-[11 \mathrm{C}]$ alkyl, $\mathrm{N}$-[18F]fluoroalkyl, $\mathrm{N}$-[11C]acyl and $\mathrm{N}[18 \mathrm{~F}]$ fluoroacyl derivatives of benzovesamicol, as well as radioiodinated derivatives (21), are all of considerable promise. We chose, due to the simplicity of the labeling reaction and the 
ready availability of high specific activity $(>5000 \mathrm{Ci} / \mathrm{mmol})[11 \mathrm{C}] \mathrm{methyl}$ iodide, to initially prepare the $\mathrm{N}$-methyl derivative, $5-[11 \mathrm{C}]$ methyl-aminobenzovesamicol ([11C]MABV). This radiotracer was prepared by simple methylation of the primary aniline and the desired [11C]MABV was isolated in high radiochemical purity $(>97 \%)$ and high specific activity $(500-700 \mathrm{Ci} / \mathrm{mmol}$ at end-of-synthesis).

We have examined the time course of regional brain distribution of pure (-)-[11C]MABV over $75 \mathrm{~min}$, or nearly 4 half-lives of carbon-11 (Figure 2). Initial uptake of radiotracer was high in all regions of the brain, followed by rapid washout from cerebellum, slower washout from cortex, and little efflux from striatum. The STR/CER, CTX/CER and STR/CTX ratios continued to increase throughout the study to maximum values of 13,5 and 2.6 , respectively. At $75 \mathrm{~min}$ the relative tissue concentrations for $(-)-[11 \mathrm{C}] \mathrm{MABV}$ are in the order of striatum $>$ cortex $>$ hippocampus $>$ hypothalamus > cerebellum, and are similar to in vitro results from autoradiography with $[3 \mathrm{H}]$ vesamicol $(4,6)$, membrane binding studies with the choline uptake inhibitor [ $3 \mathrm{H}]$ hemicholinium-3 $(20,21))$, and cholineacetyltransferase activities $(22,23,24)$. Direct comparisons of our data with previous studies must be made carefully, due to possible differences in species (rat vs. mouse vs. human), tissues chosen (cortical regions), finer spatial resolution in the autoradiographic studies, and in vitro vs. in vivo assay techniques. However, simply using the relative tissue concentrations of [11C]MABV as an estimate of specific binding with no correction for underlying non-specific binding and no assumptions regarding specific binding sites in the cerebellum, gives a dynamic range (max/min or STR/CER of 13 ) which is certainly less than that obtained for ChAT in rat brain (STR/CER of >25) but similar to the STR/CER ratios found with the other presynaptic cholinergic markers (20-24). The intermediate concentration of [11C]MABV in the cortex, expressed as a STR/CTX ratio of 2.6, is furthermore consistent with the range of STR/CTX ratios (1.8 to 4.7) found with $[3 \mathrm{H}]$ vesamicol, $[3 \mathrm{H}]$ hemicholinium-3, and ChAT activities (22-26). At 75 minutes the concentration of [11C]MABV in cerebellum, hippocampus, occipital cortex and striatum is linearly correlated $\left(\mathrm{r}^{2}=0.97\right)$ with ChAT levels in these regions of rat brain (ChAT data from Fig. 2,reference 6) . Finally, the regional brain distribution achieved here with [11C]MABV is very similar to the results recently reported for the radioiodinated derivative, 5 -[125] $]$ iodobenzovesamicol (12).

The STR/CER at $75 \mathrm{~min}$ for (-)-[11C]MABV is also quite similar to that obtained in CD-1 mice with the muscarinic receptor antagonist [11C]tropanyl benzilate ([11C]TRB) (13). Consistent with the in vitro results using [3H]vesamicol (6), however, we found a poorer correlation $\left(\mathrm{r}^{2}=0.75\right)$ of in vivo [11C]MABV concentrations with [3H]QNB binding (25) in the four brain regions studied here. The maximum target/non-target ratio obtained with [11C]MABV is significantly better than we and others have obtained with radioligands for the neuronal monoamine reuptake systems $(12,13,26,27,28,29)$.

In in vitro binding assays vesamicol shows stereoselectivity for the vesicular binding site [(-)-(R,R)-vesamicol being the more active], and thus the use of the less active isomer might afford an in vivo measure of nonspecific binding. We have examined the regional binding of the $(-)-,(t)$, and $(+)$ - isomers of [11C]MABV (Table 1). The retention of radioactivity in the brain tissues shows the stereoselectivity expected for derivatives of vesamicol, with the tissue concentrations and selectivity (as STR/CER or STR/CTX ratios) greatest for the (-)-enantiomer, intermediate for the racemic mixture, and lowest for the (+)-enantiomer The statistically lower cerebellum levels for the (t)-isomer may reflect the effect of the lower blood concentration. There was, however, some selective retention of the radioactivity in 
target tissues after administration of (+)MABV (STR/CER $=1.75$ ). It is not clear if this was due to: (a) some affinity of this "wrong" isomer for the vesamicol binding site, or (b) binding of (+)-MABV to a separate unknown site. It should be noted that vesamicol shows stereoselectivity but it does not show stereospecificity: the IC $_{50}$ value for the (+)-vesamicol is 25 -fold greater than the (-) isomer but still less than millimolar, and (+)-vesamicol has been shown in vitro to displace (-) vesamicol from vesicle membranes (5). Thus, the brain retention of (+)-[11C]MABV in this experiment may not solely represent non-specific binding of radiotracer.

Pharmacological specificity of in vivo radiotracer binding, and extent of nonspecific binding or binding to nontarget receptors, can usually be determined through the use of appropriate blocking studies. Vesamicol and its derivatives pose unusual problems in this respect, due to the reported (5) high toxicity of this class of compounds (vesamicol $\mathrm{LD}_{50}=3 \mathrm{mg} / \mathrm{kg}$; benzovesamicol $\mathrm{LD}_{50}=0.3 \mathrm{mg} / \mathrm{kg}$; toxicity of MABV is unknown). There are no other known high affinity antagonists for this binding site, and pharmacological agents which alter cholinergic function (receptor agonists or antagonist) should not affect this allosteric binding site. As the toxicity of ( \pm -vesamicol is known (5) it was chosen for these studies, and the blocking dose utilized (300 $\mu \mathrm{g} / \mathrm{kg}$ ) did not result in severe pharmacological actions or death. At 600 to $900 \mu \mathrm{g} / \mathrm{kg}$, however, the dose was $50-80 \%$ fatal. At the lower $300 \mu \mathrm{g} / \mathrm{kg}$ dose of ( \pm )vesamicol, the binding of $( \pm)-[11 \mathrm{C}] \mathrm{MABV}$ shows a consistent decrease of radiotracer retention in target areas; indicators of specific binding, calculated as either STR/CER ratios or (\%ID STR - \%ID CER) showed a 30-40\% decrease in the treated animals. Concentrations of radioactivity in the nontarget tissue (cerebellum) or blood remained unchanged. This is clearly not a full pharmacological blockade of selective radiotracer accumulation and retention, but a complete dose-response curve was not possible due to toxicity limitations. Although we cannot be sure that higher doses would block more binding sites, in those relatively few animals which survived treatment at 600 $\mu \mathrm{g} / \mathrm{kg}$ and were then studied with [11C]MABV or 5-[125I]iodobenzovesamicol (12), reductions in specific binding of 50-65\% were observed. It should be noted that the blocking doses used in this study were considerably less than doses we have commonly employed $(2-20 \mathrm{mg} / \mathrm{kg})$ for complete in vivo blockade of neurotransmitter receptor or uptake system binding sites $(9,10)$.

An important concern in use of in vivo radiotracers is the generation and tissue distribution of radiolabeled metabolites. In preliminary studies we have homogenized brain tissue of mice 45 minutes after injection of (-)-[11C]MABV and examined the extracts for presence of metabolites. This study showed no metabolites of [11C]MABV in brain tissue. This finding was consistent with the results of Jung et al (12) with [125I]iodobenzovesamicol.

In this work we have evaluated the first positron-emitter labeled radiotracer specific for the vesicles of cholinergic neurons. These in vivo results answer important initial questions in the development of a new radioligand: [11C]MABV shows regional, stereoselective retention in brain regions corresponding to known high concentrations of ChAT, HAChU, and AChE; the brain extraction and retention of radiotracer are sufficiently high to permit PET studies; and there are no radiolabeled metabolites in the target tissue. These results are encouraging and support the concept that (-)-[11C]MABV and PET can be successfully used to image the distribution of vesamicol binding sites, and thus presynaptic cholinergic neurons. The ability of this radiotracer to provide kinetic data suitable for pharmacokinetic modeling and determination of quantitative parameters (KD or $B_{\max }$ ) cannot yet be ascertained, and will require generation of tissue time-activity curves together with complete, metabolite corrected blood curves. Such studies are better and more easily 
accomplished using primates and are currently underway; using PET and monkeys we have imaged the striatum and cortex of the primate brain (K.A. Frey, M.R. Kilbourn et al, unpublished).

\section{Acknowledgements}

This work was supported by grants from the National Institutes of Health NS 24896, NS 15655, and NS 25656. The authors thank Drs. Kirk Frey, G. Keith Mulholland and Stanley Parsons for helpful discussions, and Phil Sherman and Teresa Pisani for valuable technical assistance.

\section{References}

1. P. DAVIES AND A.J.F. MALONEY, Lancet 21406 (1976).

2. P. DAVIES, Brain Res. 171 319-327 (1979).

3. R.D. TERRY AND R. KATZMAN, Ann. Neurol. 14 497-506 (1983).

4. M.R. MARIEN, S.J. PARSONS, C.A. ALTAR, Proc. Natl. Acad. Sci. 84 876-880 (1987).

5. G.A. ROGERS, S.M. PARSONS, D.C. ANDERSON, L.M. NILSSON, B.A. BAHR, W.D. KORNREICH, R. KAUFMAN, R.S. JACOBS, AND B. KIRTMAN, J. Med Chem. 32 1217-1230 (1989).

6. C.A. ALTAR AND M.R. MARIEN, Synapse 2 486-493 (1988).

7. C. MARAZANO, M. MAZIERE, G. BERGER, AND D. COMAR, Int. J. Appl. Radiat. Isot. 2849 (1977).

8. J. GLOWINSKI AND L.L. IVERSEN, J. Neurochem. 13 655-669 (1966).

9. M.R. KILBOURN, Life Sci. 42 1347-1353 (1988).

10. M.S. HAKA AND M.R. KILBOURN, Nucl. Med. Biol. 16 771-774 (1989).

11. M.R. KILBOURN, M.R. PAVIA, V.E. GREGOR, Appl. Radiat. Isot. in press.

12. Y.-W. JUNG, M.E. VAN DORT, D.L. GILDERSLEEVE, D.M. WIELAND, J. Med. Chem. 33 2065-2068 (1990).

13. G.K. MULHOLLAND, C.A. OTTO, D.M. JEWETT, M.R. KILBOURN, P.S. SHERMAN, R.A. KOEPPE, K.A. FREY, AMD D.E. KUHL, J. Labeled Compds, Radiopharm. 26 202-203 (1989).

14. R.F. DANNALS, B. LANGSTROM, H.T. RAVERT. A.A. WILSON, H.N WAGNER, Appl. Radiat. Isot. 39 291-295 (1988).

15. D.R. WEINBERGER, R.E. GIBSON, R. COPPOLA, D.W. JONES, A.R. BRAUN, U. MANN, K.F. BERMAN, T. SUNDERLAND, T.N. CHASE, AND R.C. REBA, J. Cereb. Blood Flow Metab. 9 (suppl 1) S537 (1989).

16. S.L. DEWEY, R.R. MACGREGOR, J.D. BRODIE, B. BENDRIEM, P.T. KING, N.D. VOLKOW, D.J. SCHLYER, J.S. FOWLER, A.P. WOLF, S.J. GATLEY, AND R. HITZEMANN, Synapse 5 213-223 (1990).

17. M. KHALILI, E. BROUILLET, C. CHAVOIX, M. KUNIMOTO, C. PRENANT, A. CAYLA, O. STULZAFT, B. MAZIERE, AND M.MAZIERE, J. Nucl. Med. Biophysique 12400 (1988).

18. K.A. FREY, R.A. KOEPPE, G.K. MULHOLLAND, D.M. JEWETT, R.D. HICHWA, B.W. AGRANOFF, AND D.E. KUHL, J. Nucl. Med. 29808 (1988).

19. A.A. WILSON, R.F. DANNALS, H.T. RAVERT, J.J. FROST, H.N. WAGNER Jr., J. Med. Chem. 32 1057-1062 (1989).

20. R. QUIRON, Synapse 1 293-303 (1987).

21. J. PASCUAL, A.M. GONZALEZ, AND A. PAZOS, J. Neurochem. 54 792-800 (1990).

22. W.B. STAVINOHA, S.T. WEINTRAUB, A.T. MODAK, J. Neurochem. 23 885886 (1974). 
23. D.B. HOOVER, E.A. MUTH, AND D.M. JACOBOWITZ, Brain Res. 153 295306 (1978).

24. D.L. CHENEY, H.F. LEFEVRE, AND G. RACAGNI, Neuropharm. 14 801-809 (1975).

25. M.J. MARKS AND A.C. COLLINS, Mol. Pharm. 22 554-564 (1982).

26. K.HASHIMOTO, O. INOUE, K. SUZUKI, Nucl. Med. Biol. 14 587-592 (1987).

27. S. HUME, R. MYERS, L. MANJIL, R. DOLAN, J. Cereb. Blood Flow. Metab, 9(suppl 1) S117 (1989).

28. S. RAM, K.R. KRISHNAN, G. BISETTE, J. Nucl Med. 30:1757 (1989)

29. V.L. VIILEMAGNE, R.F. DANNALS, P.M. SANCHEZ-ROA, J. Nucl. Med. 30 1753 (1989). 